\title{
"...certa ternura pelo velho Zipper!" Insatisfeito anseio pelo pai e fracasso do filho em Zipper e seu pai, romance de Joseph Roth
}

"... a certain tenderness for the old Zipper!" - unfulfilled nostalgia for the father and the son's failure in "Zipper and His Father", by Joseph Roth

\author{
Josef Christian Aigner
}

\begin{abstract}
The father-son relationship has long been a cornerstone of psychoanalytic research. This article examines one such relationship, as present in Joseph Roth's novel Zipper and His Father (Zipper und sein Vater, 1928), in the relevant historical and psycho-social context. Tracing a parallel between the fatherly figure of the Austro-Hungarian Emperor, Franz Joseph, and Arnold Zipper's father, as well as drawing upon the narrator's (and Roth's own) personal experience, the article presents an analysis of the importance of the fatherly figure and the devastating consequences of its absence.
\end{abstract}

Key-words: Father-son relationship; psychoanalytic research; Joseph Roth; Zipper und sein Vater

Resumo: A relação pai-filho é uma das pedras angulares da pesquisa psicanalítica. Este artigo examina tal relação, assim como se apresenta no romance Zipper und sein Vater (1928, Zipper e seu pai), de Joseph Roth, em um contexto histórico e psicossocial relevante. Traçando um paralelo entre a figural paternal do Imperador Austro-Húngaro, Franz Joseph, e o pai de Arnold Zipper, e valendo-se da experiência pessoal do narrador (e do próprio Roth), o artigo apresenta uma análise da importância da figura e as consequências devastadoras de sua ausência.

Palavras-chave: Relação pai-filho; pesquisa psicanalítica; Joseph Roth; Zipper und sein Vater

\footnotetext{
${ }^{*}$ Univ.-Prof. Dr. Josef Christian Aigner, Diretor e professor do Institut für Psychosoziale Intervention und Kommunikationsforschung (PsyKo) da Leopold Franzens-Universität Innsbruck, Áustria. Email: Josef.Aigner@uibk.ac.at

Agradecemos ao autor a cessão dos direitos para esta tradução. O texto em alemão foi publicado no livro: AIGNER, Josef Christian: „,... eine gewisse Zärtlichkeit für den alten Zipper“. Unerfüllte Vatersehnsucht und das Scheitern des Sohnes in Joseph Roths Roman „Zipper und sein Vater". In: LuGHOFER, Johann Georg (Hg): Im Prisma. Joseph Roths Romane. Edition Art Science, Wien - St. Wolfgang, 2009. S. 153 - 167.
} 
Aigner, J. C. - Zipper e seu pai

\section{Introdução dos editores}

Este número da Pandaemonium, dedicado às relações entre Freud e as Letras, é interdisciplinar por natureza. Por esse motivo, escolhemos traduzir um artigo de Josef Christian AIGNER - psicanalista e psicólogo, professor da Universidade de Innsbruck (Áustria) - sobre o romance Zipper und sein Vater, de Joseph Roth (1894-1939).

Roth nasceu na cidade de Brody, na época parte do Império Austro-Húngaro e hoje pertencente à Ucrânia; trabalhou como jornalista e escritor em Viena e Berlim, exilou-se na França a partir da ascensão do nacional-socialismo, em 1933. Faleceu em Paris. Escreveu inúmeros romances, novelas e ensaios, e é um dos mais importantes autores de língua alemã da primeira metade do século.

Josef C. Aigner nasceu em 1953, na Áustria, estudou Psicologia e Pedagogia na Universidade de Salzburg, onde adquiriu o título de doutor; em 2000, tornou-se livre-docente pela Universidade de Klagenfurt, com tese intitulada: "Zur Psychoanalyse von Vatererfahrung, männlicher Entwicklung und negativem Ödipuskomplex"; desde então leciona na Universidade de Innsbruck, onde também dirige o Institut für Psychosoziale Intervention und Kommunikationsforschung e desenvolve pesquisas sobre psicanálise e pedagogia, paternidade e relações homem-filho, atuação masculina na educação primária e psicanálise, inconsciente social e responsabilidade social.

Sua leitura de Zipper und sein Vater não pretende atender às expectativas de críticos literários, mas se concentra, como indicam seus interesses de pesquisas, em analisar as relações estabelecidas pelas personagens com o pai como sintomas de um contexto cultural mais amplo.

Esperamos, com a tradução de Danica Zugic Koishi, tanto oferecer a nossos leitores mais subsídios para a pesquisa sobre Roth no país quanto contribuir para o diálogo entre a germanística e outras áreas do conhecimento.

Juliana P. Perez 


\section{Aigner, J. C. - Zipper e seu pai}

Com seu pequeno romance, Zipper und sein Vater [Zipper e seu pai], de 1928, Joseph Roth nos conduz a um mundo de perda do sentido da vida e da esperança no futuro - determinadas por motivos históricos e pela Primeira Guerra Mundial -, bem como do declínio da autoridade imperial e também da autoridade paterna na experiência da geração dos filhos.

Bem, não sou um estudioso de literatura e não pretendo contribuir para com os estudos sobre o romance de Joseph Roth com esse tipo de considerações. Escrevo minha análise do texto como um psicanalista que, durante algum tempo, pesquisou intensamente os variados problemas da relação pai-e-filho e da paternidade (Cf. AIGNER 2002). E como convém a um psicanalista, que entende sua área como social e sociologicamente reflexiva, nisso também estão incorporadas, é claro, reflexões de cunho histórico e socioteórico sobre a paternidade e relação entre gerações.

Um pequeno resumo do romance retrata a família Zipper como pequeno-burgueses vienenses do final do Império Austro-Húngaro, ameaçados pelas consequências da guerra e do colapso do Império e pelo risco, que surgia ao mesmo tempo, de perda de status. O velho Zipper, filho de um carpinteiro e também amante da música, é um gerente de papelaria bastante mal-sucedido e peculiar. Ele vai levando a vida de uma maneira auto-negligente e altamente extrovertida, buscando incansavelmente contatos mais ou menos importantes e reconhecimento social e, por fim, fracassa como homem de negócios. O narrador em primeira pessoa “ Joseph Roth” é amigo de um dos filhos de velho Zipper, Arnold, e o inveja por causa de seu pai, apesar das peculiaridades deste. Este, devido ao fracasso comercial, precisa até alugar a outros um cômodo, a sala de seu apartamento, para sair de apuros financeiros. Contudo, ele conta com a simpatia do narrador. Com a eclosão da Primeira Guerra Mundial, Zipper, envia seus dois filhos, Arnold e Caesar, com entusiasmo para a guerra. Apenas Fanny, a mãe dos jovens, que sofre as agruras do casamento com Zipper, rebela-se contra o belicismo.

Após dois meses de serviço no front, Caesar Zipper é gravemente ferido, passa a vegetar e termina em um hospício, onde morre em seguida. O velho Zipper começa a duvidar do mundo e da guerra. Ele queria fazer de seus filhos, Arnold e Caesar, pessoas de sucesso. No caso de Caesar, há um fracasso completo: sua oposição ao pai e seu caráter voluntarioso fazem com que ele, mesmo antes de ir para a guerra, saia totalmente do já frágil tecido social. Porém, Arnold - retratado como gentil, bondoso e tímido -, torna-se (após o trauma da guerra) primeiro funcionário público e, depois de fracassar nesse ficar-sentado-no-escritório, 


\section{Aigner, J. C. - Zipper e seu pai}

sem sentido para ele, torna-se violinista, na melhor das hipóteses medíocre, mas de tão pouco talento que consegue apenas tocar em um café.

Arnold se casa, impulsionado mais pela perplexidade existencial, com uma amiga de infância, a atriz Erna Wilder. Mas até isso parece ser um equívoco. Erna atua em vários pequenos teatros e Arnold a acompanha em várias fases de seus trabalhos. Após alguns sucessos iniciais, Erna, que nunca amara o marido realmente, passa a viver separada dele em uma mansão luxuosa. Arnold trabalha como crítico de cinema para um jornal e a vê apenas uma vez por semana. Erna o trai com outros homens até que, durante a encenação de uma peça, sofre um ferimento que se torna crônico; por fim, ela empobrece. Arnold vai - como seu pai! - a Monte Carlo e consegue ganhar no jogo pequenas quantias, com as quais o casal mal consegue sobreviver. Enfim, Arnold termina como "palhaço musical" em um show de teatro de variedades. Como seu pai nos últimos anos de sua vida, Arnold também se torna alvo do riso dos espectadores.

Quando o narrador (Joseph Roth) finalmente retorna a Viena, ele chega a tempo apenas para o enterro. O filho, Arnold, não está presente no funeral de seu pai. Contra a opinião de um conhecido, o literato Eduard P., que acusa os pais de serem os culpados de tudo, Roth termina o romance com uma simpatia melancólica e triste pelos pais e pela Áustria decaída, por uma época que, apesar de todas suas falhas, teria oferecido mais segurança do que os novos tempos.

Zipper und sein Vater é o quinto romance de Joseph Roth; nas palavras, não totalmente compreensíveis, de Wilhelm VON STERNBURG em sua nova e recente biografia de Joseph Roth (2009: 344): "comparado a outros tem pouco enredo"" . O romance se passa no primeiro quarto do século 20 em Viena, com escapadas a Berlim e (aos cassinos de) Monte Carlo. Trata-se de um romance sobre pais e filhos, isto é um romance sobre a difícil sucessão geracional em um tempo de desvanecimento do sentido e das possibilidades de orientação. Em seu início o romance já apresenta um dos temas principais e, logo na primeira página, o tema do pai é colocado como um problema do narrador e, provavelmente, de uma geração inteira de filhos do início do século 20:

Ich hatte keinen Vater - das heißt: ich habe meinen Vater nie gekannt -, Zipper aber besaß einen. Das verlieh meinem Freund ein besonderes Ansehen, als wenn er einen Papagei oder einen Bernhardiner gehabt hätte. Wenn Arnold sagte: ,Ich gehe mit

\footnotetext{
${ }^{1}$ Igualmente não compreensível parece-me a opinião de VON STERNBURG, que aqui trata-se de um "retrato meramente psicológico do velho Zipper" (id. 2009: 344). 


$$
\text { Aigner, J. C. - Zipper e seu pai }
$$

meinem Vater morgen auf den Kobenzl', so wünschte ich mir auch einen Vater zu haben. Man konnte ihn bei der Hand nehmen, seine Unterschrift nachahmen, man konnte von ihm Rügen, Strafen, Belohnungen, Prügel erhalten. (ROTH 2003: 9).

Não tive pai, isto é: nunca o conheci, mas Zipper tinha um. Isso dava a meu amigo um prestígio especial, como se ele tivesse um papagaio ou um cachorro São Bernardo. Quando Arnold dizia: ,Vou com meu pai amanhã para o Kobenzl', eu também queria ter um pai. Poderia pegar a sua mão, imitar sua assinatura, poderia receber dele queixas, punições, recompensas, apanhar. ${ }^{2}$

Aqui se resume, praticamente, tudo que o coração de um menino cobiçava e desejava, tendo em vista a ausência do pai. Isso também se refere à biografia de Roth, à ausência real de seu pai desde cedo, por motivos de internação psiquiátrica, e se refere ao boato divulgado para ocultar esse fato (e supostamente mais ,honroso') de que ele havia cometido suicídio. O narrador - é importante observar que se trata do único romance de Roth que começa com "eu" (Cf. VON STERNBURG 2009: 346) - ocupa simultaneamente o papel do menino sem pai, e o papel de seu filho, Arnold, em cujo lugar ele evidentemente gostaria de estar, devido ao fato de Arnold ter um pai. Esse Arnold

...protzte immer mit seinem Vater. Dies hatte ihm der Vater gekauft, jenes verboten. Dies hatte er ihm versprochen, jenes versagt. Mit dem Lehrer wollte der Vater sprechen, einen Hauslehrer wollte er bestellen, Arnold eine Uhr zur Konfirmation kaufen und ihm ein eigenes Zimmer einrichten. Selbst wenn der Vater dem Sohn eine Unannehmlichkeit zufügte, so war es, als hätte Arnold sie selbst gewünscht. Der Vater war ein mächtiger, aber zugleich auch ein dienstbarer Geist. (ROTH 2003: 9).

...sempre se vangloriava do pai. O pai comprou-lhe isso, proibiu-lhe aquilo. Prometeu-lhe isso, negou-lhe aquilo. O pai gostaria de falar com o professor, ele queria contratar um professor particular, comprar um relógio para Arnold para a Crisma e arrumar um quarto só para ele. Mesmo quando o pai causava algo inconveniente para o filho, era como se o próprio Arnold a desejasse. O pai era um gênio poderoso, mas subserviente.

E ainda na primeira página do romance:

Manchmal kam ich mit Arnolds Vater zusammen. Eine Viertelstunde lang behandelte er mich wie seinen eigenen Sohn [sic!]. Er sagte mir zum Beispiel: 'Mach den Kragen zu, es geht ein Nordwest, man kann Halsweh kriegen.' Oder: ,Zeig mir mal deine Hand her, du hast dich ja verletzt, wir wollen drüben in der Apotheke gehen und etwas draufstreichen. (Id.)

\footnotetext{
${ }^{2}$ Zipper und sein Vater (ROTH 2003) - daqui em diante citado no texto como Zipper. As traduções do texto de Roth também são de Danica Z. Koishi. 


$$
\text { Aigner, J. C. - Zipper e seu pai }
$$

Às vezes, eu vinha junto com o pai de Arnold. Por uns quinze minutos, ele me tratava como seu próprio filho [sic!]. Ele me dizia, por exemplo: 'Feche o colarinho, está vindo um vento do noroeste, você pode ficar com dor de garganta.' Ou: 'Mostre a mão, você está machucado, vamos à farmácia e vamos tratar disso.'

Em tudo isso se vêem os sentimentos de admiração e anseio de um filho sem pai, bem como os gestos carinhosos e paternais de um homem perante um menininho - e não só no entender da época, mas também no de hoje! -, os mesmos que ouvimos sempre em descrições comoventes de pacientes (mulheres também!) durante a terapia.

Dann war es, als hätte mir der junge Zipper den alten geliehen. Ich war meinem Freund dankbar, hatte aber zugleich das peinliche Gefühl, daß ich ihm seinen Vater zurückgeben müsse.... Geliehene Sachen waren schließlich nicht eigene. Immerhin durfte ich zuweilen Zippers Vater längere Zeit behalten, wenn auch nur, um ihn mit Arnold zu teilen. (Id.)

Então, era como se o jovem Zipper me emprestasse o velho. Eu era grato ao meu amigo, mas ao mesmo tempo tinha a sensação desconfortável de ter que lhe devolver seu pai.... No final das contas, as coisas emprestadas não eram nossas. Mesmo assim, eu podia, por vezes, ficar com o pai de Zipper por um tempo maior, apesar de ter que compartilhá-lo com Arnold.

Esta é, portanto, a overture de uma peça sobre pais e filhos, que esboça as turbulências do tempo após a Primeira Guerra Mundial, cuja tragédia e consequências são, muitas vezes erroneamente, ofuscadas pela Segunda Guerra Mundial: a perda de milhões de homens portanto, também de pais -, e de sua integridade moral para as gerações futuras não pode ser subestimada de maneira alguma (cf. VINNAI 2004). ${ }^{3}$

Roth, como diz o narrador em Zipper, divide suas considerações em dois períodos: o período anterior à guerra, em que ele orienta suas reflexões e observações principalmente ao pai-Zipper, e o período de retorno da guerra, em que ele acompanha sutilmente o desenvolvimento do filho, Arnold, com relação a seu pai e aos acontecimentos históricos contemporâneos. Antes da guerra, Roth funde-se, por assim dizer, com o papel do filho: "Eu nunca o observava, pensava que o conhecia tão bem” (ROTH 2003: 39). Somente após seu retorno da guerra, ele de fato compreende Arnold e seus problemas, para observar, quase com a distância do narrador, o fracasso de Arnold (e o próprio?): “Ich weiß, daß mir Arnold Zipper

\footnotetext{
${ }^{3}$ Vinnai (2004) também oferece um quadro realista de como os horrores da Primeira Guerra Mundial e, posteriormente, a humilhação e ódio reprimidos representavam um pré-requisito para as perseguições veementes e ferozes na Segunda Guerra Mundial (o que ele demonstra, de forma convincente, na pessoa e no destino de Hitler).
} 


\section{Aigner, J. C. - Zipper e seu pai}

erst auffiel, als ich ihn nach dem Krieg traf." (Ibd.) [“Sei que só notei Arnold Zipper quando o encontrei após a guerra."]

Essencialmente, parece que o autor deseja compreender a situação histórica do início do século XX, marcada pela guerra e pela queda do Império, como um indício de decadência e dissolução tanto social quanto individual: seja na figura do imperador, nas figuras da família com suas crises (incluindo a relação tensa e arruinada entre o velho Zipper e sua esposa!), nas mudanças econômicas e no declínio econômico da geração dos pais ou nas incertezas pessoais relativas ao futuro dos filhos - tudo é marcado por um sentimento melancólico de fim dos tempos do qual parece ser quase impossível escapar.

Ao considerar a figura do pai na percepção do narrador, o velho Zipper parece ser um maluco esperto, que muitas vezes quer passar a perna na realidade, mas assim acaba por expor a si mesmo ao ridículo. Embora seus negócios na papelaria estivessem cada vez pior (o que ele negava sempre que possível ou "vivia ignorando"), Zipper continuava a fazer o papel de "pau-pra-toda-obra" e procurava parecer importante através de contatos aleatórios com pessoas de maior ou menor importância na vida social: "Meist gelang es ihm, die Gunst derjenigen Persönlichkeiten zu gewinnen, die man überhaupt im Leben nicht braucht." ["Na maioria das vezes, ele conseguia ganhar o favor daquelas pessoas de que você não precisa na vida de modo algum"] (RоTH 2003: 24). E ainda assim, o narrador descreve esse senhor com muita simpatia. "Basicamente, ele é um palhaço, constantemente envolvido nos empreendimentos mais ridículos, que fracassam na sua totalidade, sem que ela perca a confiança” (MuELLER 1994: 149s). Esse elemento, não perder a confiança, deve ter sido muito importante para a geração dos filhos, por volta de $1920^{4}$.

No entanto, de acordo com MuelLER (1994: 150), seria exagerado falar de uma figura paternal positiva, como afirmam certos críticos, e isso se deve principalmente ao fato de que ao filho não será oferecida "nenhuma relação intacta com a realidade", nem consigo mesmo, o que, em última instância, significa "fracassar como pai" (Ibd.).

Igualmente impressionante é a relação desastrosa entre os pais, descritas por Roth em poucas linhas, o que as torna ainda mais memoráveis:

\footnotetext{
${ }^{4}$ Isso lembra um pouco a figura trágica, mas apoiadora do pai em A vida é bela (La Vita è bella no original), filme de Roberto Benigni de 1997, em que o pai, na situação extrema de um campo de concentração, tenta dar um pouco de confiança e apoio ao filho pequeno, através de um "comediantismo", que nessa situação desesperada parece insano.
} 


$$
\text { Aigner, J. C. - Zipper e seu pai }
$$

Sie sind zwei alte Feinde, die aus Mangel an Kampfmitteln einen Waffenstillstand schließen, der aussieht wie ein Bündnis. Und man weiß nichts mehr von ihrer alten Feindschaft (ROTH 2003: 17).

São dois velhos inimigos, que, por falta de meios militares, declaram uma trégua que se parece com uma aliança. E não se sabe nada mais nada sobre sua antiga inimizade.

$\mathrm{E}$

Niemals lächelte sie in Anwesenheit ihres Mannes. Niemals beteiligte sie sich an seinen kleinen Späßen, niemals ging sie auf ein Gespräch ein... Auf seine Fragen antwortete sie mit ja oder nein. Wie mußte sie ihn hassen, verachten vielleicht! (Id.: 19)

Ela nunca sorria na presença de seu marido. Nunca participava de suas brincadeiras, nunca entrava em uma conversa... Às suas perguntas, ela respondia com sim ou não. Como ela deve tê-lo odiado, desprezado, talvez!

Tal relação entre os pais, com a qual os filhos também se identificam inconscientemente, contribui por si só para que a orientação da prole seja frágil e para que os próprios relacionamentos afetivos dos filhos tendam a rumos questionáveis. Ao menos na escolha de Arnold por sua parceira, a atriz Erna, que não o ama, o ódio presente na relação dos pais parece reavivar-se posteriormente. O "amor" - se, de alguma maneira, é possível usar essa palavra para descrever o relacionamento de Arnold - deve ser entendido antes como a busca desesperada de ser feliz e de remendar a existência, erodida e sem sentido, do que como uma tentativa de equilibrar sua fraqueza e escapar da monotonia da vida cotidiana, através de uma união com uma mulher ao menos parcialmente bem sucedida. Senão, seria difícil explicar a aquiescência às crescentes humilhações e insultos que essa mulher fazia.

No geral, o velho Zipper e seu filho, Arnold, parecem, de certa maneira, personagens quebrados, inseguros e desorientados. Em especial, Arnold, que volta da guerra, daquele berço de "jovens desorientados" (MUELLER 1994: 147) ${ }^{5}$ : não encontra mais orientação nesse pai confuso e nesses tempos caóticos. Não consegue ocupar de maneira satisfatória o cargo de de funcionário de finanças, que o velho Zipper lhe arrumou. A falta de sentido de seus atos e os comentários negativos de seu ambiente social aburguesado levam-no a desistir: gerenciamento inútil de atas, oito horas sentado no escritório etc.: "Wie soll ein Mensch, der

\footnotetext{
${ }^{5}$ Mueller chama a atenção ao fato de que esse tipo de filho desorientado está presente em todos os romances iniciais de Roth: "Theodor Lohse, Gabriel Dan, Andreas Pum, Franz Tunda, Arnold Zipper e Paul Bernheim" (1994: 147).
} 


\section{Aigner, J. C. - Zipper e seu pai}

im Krieg war, vorher nicht Beamter gewesen ist, jetzt acht Stunden täglich an einem Schreibtisch?" [ "Como é que um homem que esteve na guerra e nunca foi funcionário agora pode ficar sentado oito horas por dia a uma escrivaninha?’] (RоTH 2003: 51).

“Os filhos passam a ser cópia dos pais, sim, eles são imitações, que lhes são inferiores até em vitalidade e capacidade de viver" (KARLSTETTER 1980: 144). O filho de Zipper carece daquela fé ingênua no factível, que caracteriza seu pai - por mais realista e ameaçado pelo fracasso que seja. Ele e sua geração não dominam mais, nas novas circunstâncias, a arte da vida que se autoparodia e que marcou o velho Zipper (e a geração pré-guerra). Ao contrário, refletem-se em Arnold o ensimesmamento e a fraqueza apática, causadas pelas instáveis condições sociais e econômicas, e pela consequentes inseguranças pessoais que é típica dessa geração (cf. KARLSTETTER 1980: 126).

Es war, als besäße der Sohn schon das Wissen von der eigenen Lächerlichkeit seiner selbst und wäre deshalb tragisch; während der Vater noch die gleiche Eigenschaft mit dem siegreichen Stolz eines Menschen trug, der zu wissen glaubt, daß er gerade infolge dieser Anlage triumphieren wird. (ROTH 2003: 94)

Era como se o filho já estivesse consciente do próprio ridículo e fosse, portanto, trágico; enquanto o pai ainda exibia a mesma característica com o orgulho triunfante de um homem que acredita saber que vencerá justamente graças a essa disposição.

A geração dos filhos, comparada com a geração dos pais, teve, por assim dizer, a desvantagem de ter consciência das novas condições, às quais os pais ainda não haviam chegado e já não chegarão, as quais, em virtude da reflexão sobre o fracasso necessário dos pais, deviam lhe trazer medo e incerteza. Isso também se reflete de maneira psicologicamente desvantajosa - como podemos dizer a partir da experiência psicanalítica - porque nessas condições não é mais possível um confronto produtivo com os pais, nem sua deposição significativa. Só assim o drama dos "filhos pródigos" torna-se realmente compreensível no exemplo do irmão Caesar, que impressiona menos como o "filho pródigo" do que o "sacrificado": sua inadequação significava então o fracasso total, a marginalização, enlouquecimento devido às circunstâncias (cf. MUELLER 1984: 151).

Roth situa a estória em Viena, no tempo de Império decadente, ou seja, no tempo de seu fim. Isso possui um significado especial e, provavelmente graças a seu acentuado dom de observação, é assim - com a desmontagem do imperador como uma figura paterna e de suas consequências psicológicas em massa - que Roth traça um paralelo entre o enfraquecimento estatal e individual da autoridade paterna (e, por fim, dos pais). Esse paralelo também foi 


$$
\text { Aigner, J. C. - Zipper e seu pai }
$$

traçado pela psicologia social psicanalítica, embora claramente muito mais tarde (cf. FEDERN 1919). Mario ERDHEIM, etnopsicanalista de Zurique, refere-se exatamente a essa relação em seu trabalho marcante, Produção social da inconsciência [Die gesellschaftliche Produktion von Unbewusstheit] (1982). Ele escreve o seguinte sobre a figura e o significado do Imperador Franz Joseph I:

\begin{abstract}
Franz Joseph war nicht nur der Krieger, sondern auch der mächtige Vater, der in der ,landesväterlichen Liebe' dem Volk seine ,volle Fürsorge‘ zuwendete, und - nachdem er alles geprüft und erwogen - ruhigen Gewissens seine Pflicht tat und für die Ehre, Größe und Macht des Vaterlandes zu den schwersten Opfern aufrief. Solch einen Vater zu haben, mußte die Söhne mit Stolz erfüllen, und sie danach streben lassen, wie er zu werden, und das hieß auch, die Dinge so zu sehen, wie er sie sah. (1982: 381).

Franz Joseph não foi somente $o$ guerreiro, mas também o pai poderoso, que através do 'amor do pai da pátria' proporcionava ao povo seu 'cuidado absoluto' e, depois de ter verificado e considerado tudo, com a consciência limpa fazia seu dever e clamava pelos mais difíceis sacrifícios em nome da honra, grandeza e poder da pátria. Ter um pai assim deve ter enchido os filhos de orgulho, devem ter se esforçado a ser como ele, o que também significava ver as coisas com seus olhos.
\end{abstract}

Erdheim qualifica o fenômeno da "fé no imperador-pai" até como uma experiência de "política mundial como variação da história familiar" (Ibd.: 382). Nesse caso, através da "transferência" - como na psicanálise são chamados os sentimentos pelas pessoas de referência significativas no passado biográfico atualizados como pessoas ou mesmo instituições no presente ("Estado-Pai") -, os sentimentos pelo pai são dirigidos inconscientemente ao imperador e à monarquia que ele representa. Isso é também confirmado várias vezes na literatura histórica:

Den politischen Übervater repräsentierte Kaiser Franz Joseph. Ihm wurden alle Vatertugenden zugeschrieben.... Er hielt das Reich zusammen. Sein Tod im Herbst 1916 bedeutete für viele das Ende der Monarchie. Bruno Kreisky erinnerte sich an die Düsternis der Tage. ,Als das Trauerkondukt endlich herauskam, schien es mir, als fülle sich die ganze Welt mit Schwarz' (HANISCH 2005: 290).

O Imperador Franz Joseph representava o patriarca político. A ele foram atribuídas todas as virtudes paternais.... Ele mantinha o império unido. Sua morte, no outono de 1916, significou para muitos o fim da monarquia. Bruno Kreisky lembrou assim da tristeza do dia. 'Quando o cortejo fúnebre finalmente veio, tive a impressão de que o mundo inteiro se encheu de preto'.

O luto pela monarquia era bastante difundido nos círculos intelectuais e artísticos e foi vivenciado por muitos, mais ou menos conscientemente, como perda do pai. O núcleo mais 


\section{Aigner, J. C. - Zipper e seu pai}

íntimo da monarquia teve uma conotação paternal: "Pai do Céu”, "Santo Pai", "Pai da Pátria", "pai da família" têm qualidades emocionais muito próximas (Ibd.: 292). Nesse sentido, as experiências dramáticas da perda dessa geração de Arnold Zipper e do narrador tornam-se, da perspectiva da teoria psicanalítica cultural, ainda mais compreensíveis.

"Ein ähnlich starkes Bedürfnis aus der Kindheit wie das nach dem Vaterschutz wüßte ich nicht anzugeben” [ "Eu não saberia especificar uma necessidade da infância tão forte como a de proteção paternal']: assim o criador da psicanálise atribuía ao pai um significado muito excepcional, desde a infância (FREUD 1927: 204; ênfase JCA). Joseph Roth escreveu um romance em que essa necessidade é claramente ilustrada à luz da orfandade individual e das perdas de paternidade coletiva, provedora de segurança, que foram determinadas pela história.

Esse pai também pode ser imperfeito, nas fases cruciais de desenvolvimento dos filhos (e filhas), ele precisa, sim, ser até "combatível" ["bekämpfenswert"] (o que a psicanálise denomina complexo de Édipo, que ocorre uma vez na infância e depois com repetição modificada na adolescência)! Mas ele deve estar presente, ao menos como representação mental, e não pode ser anulado pelas circunstâncias sociais! Só assim o pai pode também ser superado, pode acontecer uma "reconciliação" [Ver-Söhnung] em função do desenvolvimento, especialmente o masculino. Essa superação necessária e a concomitante "desidealização" do pai alimentam o passo de maturação rumo à vida adulta e, finalmente, ao próprio tornar-se pai. Caso contrário, faltam uma etapa importante de maturação e a orientação dela resultante para as próprias vidas dos filhos e filhas. Não é por acaso que em Zipper, de Roth, nem se mencione a paternidade do filho, ela é dificilmente imaginável.

Por fim, o narrador em primeira pessoa desencanta ainda esse imperfeito e velho pai Zipper de suas habilidades, com as quais ele, ainda garoto, havia sonhado: ele teria feito tudo errado, havia comprado na farmácia algo inadequado para a mão machucada do menino, suas piadas eram ruins, sua seriedade ridícula. Ele era um carpinteiro, que não sabia fazer nada e que só sabia tocar ao violino uma canção - e nem isso muito bem -, uma canção triste, que ele erroneamente achava alegre. "Porém", como diz o final do romance, "ele preenchia meus dias. Arnold, às vezes, o emprestava a mim" [“Aber er hatte doch meine Tage ausgefüllt. Arnold hatte ihn mir manchmal geliehen.”] (RоTH 2003: 103).

Ao menos isso, ao menos um pai emprestado. Já é alguma coisa.

Tradução de Danica Zugic Koishi Revisão de Juliana P. Perez 
Aigner, J. C. - Zipper e seu pai

\section{Referências Bibliográficas}

AIGNER, Josef Christian. Der ferne Vater: Zur Psychoanalyse von Vatererfahrung, männlicher Entwicklung und negativem Ödipuskomplex. Gießen: Psychosozial, 2002.

ERDHEIM, Mario. Die gesellschaftliche Produktion von Unbewusstheit: Eine Einführung in den ethnopsychoanalytischen Prozess. Frankfurt a.M.: Suhrkamp, 1982.

FEDERN, Paul. Zur Psychologie der Revolution: Die vaterlose Gesellschaft (1919). In: DAHMER, Helmut (Org.) Analytische Sozialpsychologie. V. 1. Frankfurt a.M.: Suhrkamp, 1980, p. 63 - 87.

FREUD, Sigmund. Die Zukunft einer Illusion (1927). In: Studienausgabe. V. IX, Frankfurt a.M.: Fischer, 1974. p. 135 - 189.

HANISCH, Ernst. Männlichkeiten: Eine andere Geschichte des 20. Jahrhunderts. Viena: Böhlau, 2005.

KARLSTETTER, Klaus. Das Bild des Jugendlichen in der deutschsprachigen Erzählliteratur der Zeit zwischen dem Ersten Weltkrieg (1918) und der Diktatur (1933). Stockholm: Almquist \& Wiksell International, 1980.

MUELLER, Thomas. Joseph Roths Zipper und sein Vater. In: GAEDE, Friedrich; O’NEILL, Patrick; SCHECK, Ulrich (Orgs.): Hinter dem schwarzen Vorhang: Die Katastrophe und die epische Tradition. Festschrift für Anthony Riley. Tübingen: A. Francke, 1994, p. 147 - 155.

NÜRNBERGER, Helmuth. Joseph Roth. Reinbek b. Rowohlt, Hamburg: rororo, 1981.

ROTH, Joseph. Zipper und sein Vater. Köln: Kiepenheuer \& Witsch, 2003.

VINNAI, Gerhard. Hitler - Scheitern und Vernichtungswut: Zur Genese des faschistischen Täters. Gießen: Psychosozial Verlag, 2004.

VON STERNBURG, Wilhelm. Joseph Roth: Eine Biografie. Köln: Kiepenheuer \& Witsch, 2009. 